Ecology, 2003, Volume 84, Issue 12, Pages 3339-3348

ISSN: (Print 0012-9658) (Online 1939-9170)

DOI: $10.1890 / 02-0444$

http://www.esajournals.org/loi/ecol

http://www.esajournals.org/doi/pdf/10.1890/02-0444

Copyright 2003 by the Ecological Society of America

\title{
Scale-Dependent Associations Among Fish Predation, Littoral Habitat, and Distributions of Crayfish Species
}

\author{
James E. Garvey \\ Fisheries and Illinois Aquaculture Center, Department of Zoology, Southern Illinois University \\ Jessica E. Rettig \\ Department of Biology, Denison University
}

\section{Roy A. Stein}

Aquatic Ecology Laboratory, Department of Evolution, Ecology, and Organismal Biology, The Ohio State University

David M. Lodge

Department of Biological Sciences, University of Notre Dame

\section{Steven P. Klosiewski}

Division of Fisheries and Habitat Conservation, U.S. Fish and Wildlife Service,

\begin{abstract}
To predict how species establish and disperse within novel communities, the spatial scale at which competition, predation, and habitat interact must be understood. We explored how these factors affect the distribution and abundance of the exotic crayfishes Orconectes rusticus and O. propinquus and the native $O$. virilis at both the site-specific and whole-lake scales in northern Wisconsin lakes. During summer 1990, we quantified crayfish, fish predators, and fish diets in cobble and macrophyte sites in Trout Lake, comparing resulting patterns to those in 21 lakes surveyed during summer 1987. Within and across lakes, fish abundance was unrelated to habitat. Within Trout Lake, O. rusticus and O. propinquus were common in both cobble and macrophyte. Orconectes virilis was restricted to macrophyte, probably due to strong displacement by the invaders in cobble. Across lakes, $O$. rusticus increased where habitat was more than $16.7 \%$ cobble, O. propinquus was generally rare, and $\mathrm{O}$. virilis abundance was unrelated to cobble. Crayfish were generally small in cobble and large in macrophyte, perhaps because of habitat-specific, sizeselective fish predation or because large crayfish leave cobble when it no longer provides refuge. Orconectes virilis, the largest of three congeners, may have a size refuge in macrophyte but not in cobble. Across lakes, $O$. rusticus was only abundant when fish biomass was low; $O$. virilis abundance varied positively with fish.

Effects of fish predation and habitat on the ability of invaders Orconectes rusticus and $O$. propinquus to establish and replace $O$. virilis appear to be scale dependent. At local (site-specific) scales, cobble likely interacts with selective predation for $O$. virilis to allow the invaders to establish and replace the native. At the lake-wide scale, high cobble facilitates invaders but predation may curb their successful dispersal and establishment at new sites. Models of community assembly and invasions need to incorporate scale dependencies in habitat availability and biotic interactions to effectively assess the invasion potential of novel species.
\end{abstract}

\section{Introduction}

Community ecologists seek to understand mechanisms underlying the persistence and 
establishment of species (Elton 1958, Wellborn et al. 1996). Given that introductions of exotic species are increasing at an unprecedented rate (Kolar and Lodge 2001), understanding how invaders successfully establish, disperse, and modify the abundance and distribution of native species also has become important within the disciplines of conservation and resource management (Lodge et al. 2000).

Both competition and predation structure communities (Sih et al. 1985, Northcote 1988, Stein et al. 1995) and thus affect invasions (Abrams 1996, Hill and Lodge 1999, Miller et al. 2002). The relative sizes and behaviors of species influence invasions by altering interactions (Kiesecker and Blaustein 1998, Holway and Suarez 1999). If predators reduce the density or dispersive ability of invaders, then establishment of these species will be suppressed (Lodge 1993). Still, characteristics such as high aggression or unique morphology (e.g., large size, claws, or body armor) may render invaders successful by reducing predatory susceptibility and eliminating competitors (Garvey et al. 1994, Holway and Suarez 1999). Although interactions often occur initially at relatively small, local scales, established invaders may disperse from these localities and dramatically alter ecosystems (Vitousek 1990, Lodge and Hill 1994, VanderZanden et al. 1999).

In northern Wisconsin (USA) lakes, the invading crayfish Orconectes rusticus has been replacing the native $O$. virilis and a previous invader $O$. propinquus since it was introduced $>35$ years ago (Capelli 1982, Lodge et al. 1986, Olsen et al. 1991). Similar replacements are occurring among other crayfishes (Butler and Stein 1985, Corey 1988, Söderbäck 1990, Lodge et al. 2000). Orconectes virilis is the largest of the three congeners. Although large size often reduces the vulnerability of crayfish to gape-limited fish predators (Stein 1977, Garvey et al. 1994, Kershner and Lodge 1995), O. rusticus is more aggressive and outcompetes its congeners for refuge, rendering it less vulnerable to predation in sympatry (Capelli and Munjal 1982, DiDonato and Lodge 1993, Garvey et al. 1994). Although O. rusticus may successfully replace its congeners at contact zones, complete species replacements within lakes do not appear to be rapid (Byron and Wilson 2001). Cobble (diameter 64-256 mm) substrate may affect the establishment and dispersal of $O$. rusticus, because it provides more refuge than sand and vegetation (Kershner and Lodge 1995). Without adequate refuge, predation may slow lake-wide dispersal rates of $O$. rusticus (Kershner and Lodge 1995, Byron and Wilson 2001) by reducing activity (Collins et al. 1983) and perhaps increasing mortality of dispersers.

To determine how habitat type and fish assemblages affect crayfish abundance and species composition, we sampled fish and crayfish intensively in Trout Lake, Wisconsin, and extensively in 21 additional lakes. In Trout Lake, we explored relationships among habitat type, fish abundance and fish diets, and crayfish species composition, size structure, and abundance. Across lakes, we tested the generality of patterns in Trout Lake by associating fish abundance, habitat availability (i.e., cobble), and crayfish species composition. Crayfish sizes should vary with local-scale habitat type and fish abundance, ultimately affecting the establishment of $O$. rusticus and persistence of its congeners at the whole-lake scale. Cobble should positively affect the abundance of O. rusticus (see Lodge and Hill 1994), whereas increasing predation should reduce its lake-wide abundance.

\section{Methods}

Trout Lake

We quantified crayfish and their fish predators in Trout Lake, a large (1570 ha) mesotrophic lake in Vilas County, Wisconsin, during June through August 1990. We compared 
crayfish size distribution and abundance between three littoral sites dominated by cobble (i.e., 64-256 mm diameter rocks) and three comprised of macrophyte (mostly Elodea spp. and Potamogeton spp.). Each site was $500 \mathrm{~m}$ long, adjacent to patches of sand, and between one and three $\mathrm{m}$ deep. All sites were at least $1000 \mathrm{~m}$ apart. Cobble sites 1 and 2 and macrophyte site 1 were both in the south-southeast portion of Trout Lake, where O. rusticus was established (Lodge et al. 1986). Macrophyte site 2 was located on the western shore, where the status of $O$. rusticus was unclear. Both cobble site 3 and macrophyte site 3 were in the northern portion of the lake, where $O$. rusticus was absent. Orconectes propinquus was established throughout the lake (Lodge et al. 1986). Within each site, we quantified densities, species composition, and size distributions of crayfish, yellow perch Perca flavescens, largemouth bass Micropterus salmoides, smallmouth bass $M$. dolomieu, walleye Stizostedion vitreum, and rock bass Ambloplites rupestris.

Between 2100 and 2400 hours on three nights (with at least $48 \mathrm{~h}$ between each night), fishes were sampled with boat-mounted, direct current electrofishing at each 500-m transect. For each transect, we identified, counted, and measured (total length, TL, to the nearest $1.0 \mathrm{~mm}$ ) each fish. Because fish size may affect the quantities and sizes of crayfish consumed, we pooled all fishes into three size classes: small ( $<150 \mathrm{~mm}$ TL), medium (150-299 mm TL), and large ( $\geq 300 \mathrm{~mm}$ TL). Number per site was averaged across the three nights, with sites as replicates. We analyzed density differences with respect to size class and habitat using multivariate analysis of variance (MANOVA, Proc GLM, Type III sums of squares; SAS 1996). In addition, three separate one-way ANOVAs compared abundance of each size class between habitats.

Within each transect, we sampled diets using gastric lavage (Seaburg 1957), which were quantified by identifying crayfish species and carapace length (CL, the distance between the tip of the rostrum and the posteriomedian edge of the carapace). When only chelae were recovered, crayfish size was back calculated using chela length vs. CL regressions (Garvey and Stein 1993). Although a few chelae in diets might have been regenerated and thus would have been smaller than normal, effects on estimated CLs were likely small. Dry mass (g) of crayfish and other prey items also was quantified.

Crayfish were sampled midway along each 500-m cobble or macrophyte transect. In cobble, ten $1-\mathrm{m}^{2}$ quadrats were dropped haphazardly; SCUBA divers collected all crayfish within each the following morning. In macrophytes, a pop-net consisting of netting attached between a weighted $1-\mathrm{m}^{2}$ quadrat base and a buoyant $1-\mathrm{m}^{2}$ top was used, preventing escape. Otherwise, the protocol was identical to quadrats. Crayfish species, sex, and CL (to the nearest $0.5 \mathrm{~mm}$ ) were quantified. Mean crayfish per square meter was computed across sites for each habitat and compared (Proc TTEST, SAS 1996). For each species (excluding O. virilis, which was generally rare) pooled across sites, we compared mean CLs with $t$ tests (SAS 1996).

For fish diets, we averaged fish stomach contents within each replicate site. The percentage of fish containing crayfish and the percentage dry mass of stomach contents were compared between habitats using $t$ tests. We determined how size selection of crayfish by fish predators depended on fish size and habitat type with analysis of covariance (ANCOVA), including crayfish CL, fish size, and habitat (Neter et al. 1990; Proc GLM, SAS 1996).

To assess fish preference for crayfishes, we regressed (least squares linear regression) the proportion of species at each site against the proportion of species in pooled diets at each site. A slope of one indicated that species were selected in proportion to their relative abundance. Slopes greater than or less than one suggested that crayfishes were either consumed proportionally more or less than expected, respectively. To quantify size-selective predation, we grouped crayfish 
into three CL classes for those caught in the field and in stomachs: small (10.0-19.0 mm), medium (20-29.5 mm), and large (30-39.5 mm). Selectivity was determined using Chesson's $\alpha$ (Chesson 1978, 1983):

$$
\alpha_{i}=\frac{\left(r_{i} / n_{i}\right)}{\sum\left(r_{i} / n_{i}\right)}
$$

where $r_{i}$ is the proportion of prey, $i$, in the stomach; $n_{i}$ is the proportion of prey, $i$, in the environment; $\alpha$ ranges from 0 to 1 . When $\alpha_{\mathrm{i}}>1 / \mathrm{m}$, where $m$ is the number of prey, the prey is taken more often than would be predicted and is preferred. When $\alpha_{i}=1 / m$, prey selection is random. A prey item is avoided if $\alpha_{i}<1 / \mathrm{m}$. $\alpha$ was determined for each size of prey in each replicate site. Mean $\alpha$ values for each size class were compared between the two habitats using $t$ tests.

\section{Among lakes}

Fish and crayfish were sampled in 21 northern Wisconsin lakes $\left(45-46^{\circ} \mathrm{N}\right)$ ranging widely in area (21-518 ha; median $106 \mathrm{ha}$ ) and depth (2-27 m; median $7 \mathrm{~m}$ ) during summer 1987 (Lodge et al. 1998). We determined the number of habitats (open substrate, macrophyte, cobble) within each lake. We then designated 12 sectors for each habitat and lake, causing sampling effort to increase as habitat heterogeneity increased (36 sectors for lakes with three habitats, 24 for lakes with two habitats, and 12 for lakes with one habitat). From this, we estimated the proportion of lake littoral zone comprised of each habitat (see Kershner and Lodge 1995). Within each sector, we set one minnow trap overnight for crayfish during the period July 22 through August 26 using the standard bait (beef liver) and trap opening (Lodge et al. 1986). Abundances of large-mouth bass, yellow perch, rock bass, smallmouth bass, and walleye were quantified with night, boat electrofishing along 50-m transects (June 1-August 31) in 5-11 sectors per lake, including all habitats. Crayfish and fish were identified, counted, and measured (CL or TL). We converted individual fish lengths to biomass (g) using regressions (Carlander 1969, 1977, 1997).

To determine whether fish abundance differed among habitats, we averaged their number and biomass within each habitat and compared habitat-specific means across lakes with analysis of variance (ANOVA, Proc GLM, SAS 1996; lakes were considered replicates). Otherwise, lakewide crayfish (number per trap) and fish (number or biomass per transect) abundances were averaged across all sectors within each lake.

If site-specific interactions between crayfishes are important, their associations should be stronger at the site-specific rather than the whole-lake scale. Because relationships between the species were nonlinear, we used a two-dimensional Kolmogorov-Smirnov (2DKS) test at each spatial scale to test the null hypothesis that species abundances were independent (Garvey et al. 1998). Each test determined the maximum point of departure between the observed and expected distributions, which often occurs at a threshold change in variance (Garvey et al. 1998). Significance was determined by rerandomizing the observed $X, Y$ pairs 5000 times (Manly 1991), determining the proportion of random differences exceeding the observed one. Because previous analyses of portions of these data revealed that cobble affects crayfish (Lodge and Hill 1994, Kershner and Lodge 1995), we also quantified associations between lake-wide crayfish abundance and the proportion of cobble among lakes using the 2DKS.

We explored relationships among lake-wide abundances of crayfishes and fishes in the context of environmental variables (lake depth, surface area, and percent cobble) using canonical 
correspondence analysis (CCA, McCune and Mefford 1999). Species abundances and the three environmental variables were included in the species and environmental matrix of the CCA, respectively. Scores for lakes were centered and scaled to represent the weighted mean scores for species. Pearson correlation coefficients determined the direction of associations between species abundances and species scores. Environmental biplot scores were plotted with the species scores to explore associations among environmental characteristics, lakes, and species. CCA species scores were used to select fishes that may affect both local and lake-wide crayfish abundances. We then determined whether bivariate distributions of the combined biomass of these fishes and abundances of each crayfish species could occur randomly using the 2DKS at both the amongsector and the whole-lake scale (Lodge et al. 1998).

\section{Results}

Trout Lake

All fishes occurred in both cobble and macrophyte in Trout Lake (Table 1). Mean number of fish per transect was similar between habitats (Table 1; MANOVA: habitat effect, Wilk's $\left.\lambda, F_{3,2}=7.06, P=0.13\right)$. However, large fish $(\geq 300 \mathrm{~mm}$ TL) were less frequent in cobble than in macrophyte $(0.67 \pm 0.19$ individuals/ transect, \pm 1 SE VS. $1.89 \pm 0.22$; one-way ANOVA: $\left.F_{1,5}=17.29, P=0.014\right)$. Smaller fish did not differ in abundance among habitats. Abundances of fish less than $150 \mathrm{~mm}$ TL were $9.33 \pm 3.66$ and $15.67 \pm 3.34$ in cobble and macrophyte, respectively (one-way ANOVA: $F_{1,5}=1.64, P=0.27$ ). Those of fish between $150-299 \mathrm{~mm}$ TL were $11.67 \pm 3.20$ and $14.89 \pm 1.11$ in cobble and macrophyte (one-way ANOVA: $F_{1,5}=0.90, P$ $=0.40)$.

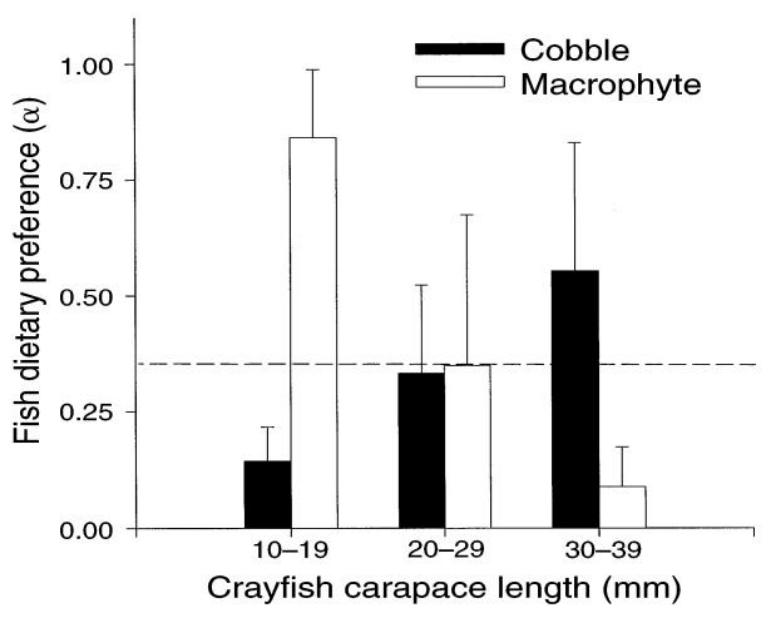

Fig. 1. Mean (+1 SE) fish dietary preference $(\alpha)$ for small, medium, and large crayfish in three cobble and three macrophyte sites in Trout Lake, Wisconsin during the summer of 1990. The dashed line indicates a neutral preference $(\alpha=1 / m$, where $\mathrm{m}$ is the number of prey).

Crayfish species and densities differed among sites both within and between habitats in Trout Lake. Orconectes virilis occurred exclusively in macrophyte. All three species co-occurred at only one site, with the order of abundance being $O$. propinquus, $O$. rusticus, and $O$. virilis $\left(2.3,1.2\right.$, and 0.6 individuals $/ \mathrm{m}^{2}$, respectively). Orconectes rusticus only occurred in lower Trout Lake and was abundant at only one cobble site (>90\% of individuals). In cobble, mean crayfish per $\mathrm{m}^{2} \pm 1$ SE was $19.1 \pm 18.9,6.2 \pm 1.5$, and $0.0 \pm 0.0$ for $O$. rusticus, O. propinquus, and $O$. 
virilis, respectively. In macrophyte, $O$. rusticus, $O$. propinquus, and $O$. virilis densities were 0.4 $\pm 0.4,3.6 \pm 2.4$, and $0.3 \pm 0.2$, respectively. Total crayfish densities were $6.9 \pm 1.2$ in cobble and $4.3 \pm 2.3$ in macrophyte (pooled $t$ test: $\mathrm{df}=4, P=0.47$ ).

Mean CLs of $O$. rusticus and $O$. propinquus were larger in macrophyte (O. rusticus: mean $\pm 1 \mathrm{SE}=30.2 \pm 0.8, N=27 ;$ O. propinquus: $24.6 \pm 0.3, N=139)$ than in cobble $(O$. rusticus: $17.9 \pm 0.6, N=59$; O. propinquus: $17.6 \pm 0.4, N=198$; pooled $t$-tests for both species, $P=0.0001)$. In macrophyte, mean CL of $O$. virilis $(32.2 \pm 1.1, N=16)$ was larger than $O$. propinquus but not $O$. rusticus (Fig. 1 ; one-way ANOVA: $F_{2,179}=52.08, P=0.0001$; Scheffe's between $O$. virilis and $O$. propinquus: $P=0.0001$; between $O$. virilis and $O$. rusticus: $P=0.24$ ).

Crayfish were consumed in both habitats, occurring most frequently in largemouth bass and yellow perch and least frequently in walleye (Table 1). Neither the percentage of fishes containing crayfish nor the percentage of crayfish comprising diets differed between habitats (Table 1; all fishes pooled, $t$ tests, $P>0.05$ ). As fish size increased, crayfish size eaten increased (ANCOVA: fish size, $F_{1,100}=30.9, P=0.0001$ ). A fish size $\times$ habitat effect (ANCOVA: $F_{1,100}, P$ $=0.025)$ indicated that slopes for cobble and macrophyte habitats were unequal, likely because fish and crayfish size were positively related in cobble $\left(N=58, R^{2}=0.36, P=0.0001\right.$, slope $=$ $0.0735)$ but not in macrophyte $\left(N=46, R^{2}=0.048, P=0.15\right.$, slope $\left.=0.0248\right)$. In both habitats, fishes of all sizes consumed crayfish, with fish lengths ranging 75-350 mm TL (total length).

Within cobble and macrophyte, $93 \%$ and $78 \%$ of the consumed crayfishes could be identified. Across all cobble sites, $70 \%$ of the crayfish in diets were O. propinquus and $30 \%$ were $O$. rusticus. Across macrophyte sites, O. propinquus, $O$. rusticus, and $O$. virilis occurrences were 64,11 , and $25 \%$, respectively. Relative proportions of each species occurring in the field and in diets at each site were positively related $\left(N=6\right.$ for each test; $O$. rusticus, $R^{2}=0.99, P=$ $0.0001 ; O$. propinquus, $R^{2}=0.86, P=0.005 ; O$. virilis, $R^{2}=0.97, P=0.0002$ ). Slopes for $O$. rusticus and $O$. propinquus did not differ from 1, indicating that they were consumed in proportion to their relative abundance. A slope of 0.4 for $O$. virilis suggested it was consumed less than expected.

Table 1. Mean (with 1 SE in parentheses) number of fish captured, percentage of fish containing crayfish, and percentage of crayfish tissue (by dry mass in $\mathrm{g}$ ) in fish diet collected at three cobble and three macrophyte sites in Trout Lake, Wisconsin, during June-August 1990.

\begin{tabular}{llccc}
\hline \hline Habitat & Species & $\begin{array}{c}\text { Individual fish } \\
\text { captured in } \\
\text { each habitat }\end{array}$ & $\begin{array}{c}\text { Fish containing } \\
\text { crayfish (\%) }\end{array}$ & $\begin{array}{c}\text { Dry mass of } \\
\text { crayfish in } \\
\text { diet (\%) }\end{array}$ \\
\hline Cobble & YP & $16(9)$ & $80(14)$ & $86(3)$ \\
& RB & $8(1)$ & $76(13)$ & $59(8)$ \\
& SMB & $18(14)$ & $50(25)$ & $84(9)$ \\
& WE & $6(0.6)$ & $25(17)$ & $27(18)$ \\
& LMB & $0.3(0.3)$ & $100 \dagger$ & $99 \dagger$ \\
Macrophyte & Spp. pooled & $49(12)$ & $59(16)$ & $66(12)$ \\
& YP & $29(8)$ & $48(6)$ & $83(9)$ \\
& RB & $20(5)$ & $26(17)$ & $74(0.4)$ \\
& SMB & $7(4)$ & $47(23)$ & $57(13)$ \\
& WE & $12(4)$ & $34(17)$ & $10(5)$ \\
& LMB & $1(1)$ & $50(50)$ & $99 \dagger$ \\
& Spp. pooled & $71(7)$ & $40(2)$ & $57(5)$ \\
\hline
\end{tabular}

Notes: Fish predators were yellow perch (YP) Perca flavescens, rock bass (RB) Ambloplites rupestris, smallmouth bass (SMB) Micropterus dolomieu, walleye (WE) Stizostedion vitreum, and largemouth bass (LMB) M. salmoides.

$\uparrow$ Only one individual was analyzed. 


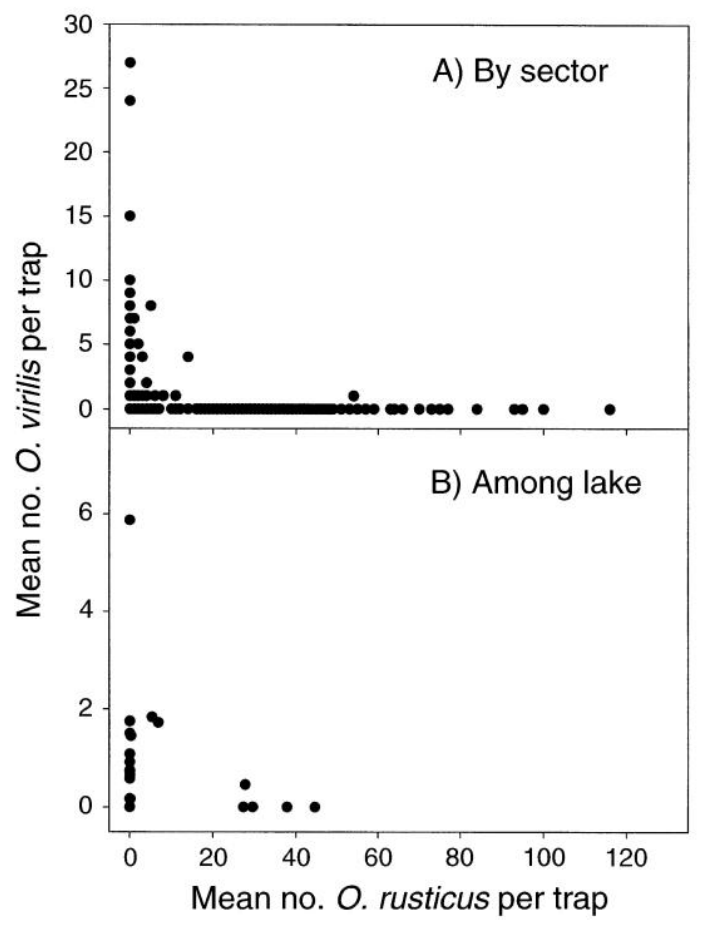

Fig. 2. (A) Sector and (B) mean lake-wide abundances of $O$. rusticus and $O$. virilis in the littoral zones of 21 northern Wisconsin lakes during the summer of 1987.

Because habitat-specific sizes were similar for all crayfishes, we pooled species for calculation of fish size preference. Fishes selected small crayfish more intensely in macrophyte than in cobble (Fig. 1, $t$ test: $P=0.02$ ). Medium crayfish were selected equally in cobble and macrophyte. Selectivities between cobble and macrophyte for large crayfish did not differ because, at one of the three cobble sites, no large crayfish occurred in fish. However, at the other two cobble sites, a values were 0.85 and 0.81 for large crayfish (mean $\alpha$ value for large crayfish in macrophyte $=0.089$, Fig. 1).

\section{Among lakes}

For fishes, neither mean number per transect nor mean biomass per transect differed among macrophyte, cobble, and open areas among lakes (one-way ANOVA: number, $F_{2,43}=$ $0.18, P=0.83$; biomass, $F_{2,49}=2.1, P=0.12$ ). Because $O$. propinquus was only $2 \%$ of total crayfish, we focused on $O$. rusticus and $O$. virilis. At the sector-specific scale, $O$. virilis trap abundance varied greatly below 6 individuals per trap but was low and invariant above this apparent threshold (2DKS, $P=0.0002$; Fig. 2A). Species associations at the whole-lake scale did not differ from random (2DKS, $P=0.22$; Fig. 2B). For $O$. rusticus, mean abundance and variance increased beyond a threshold of $16.7 \%$ cobble in lakes (Fig. 3A; 2DKS, $P=0.01$ ). Conversely, no pattern between cobble and abundance of $O$. virilis emerged (Fig. 3B; 2DKS, $P=$ $0.19)$.

The CCA revealed associations among lakes with different mean abundances of $O$. rusticus, $O$. virilis, and the five fishes, in the context of cobble, depth, and surface area. The first and second axes for the species data explained 39.9 and 3.2\% of the variance, respectively (Table 2). Species scores in the first axis were positive for $O$. virilis, yellow perch, rock bass, and largemouth bass 
and negative for $O$. rusticus, small-mouth bass and walleye (Table 2; Fig. 4). The biplot scores for area, depth, and cobble generated from the environmental data were all negatively correlated with species axis 1 (Pearson correlation: area, -0.582; depth, -0.641; cobble, -0.933; Fig. 4).

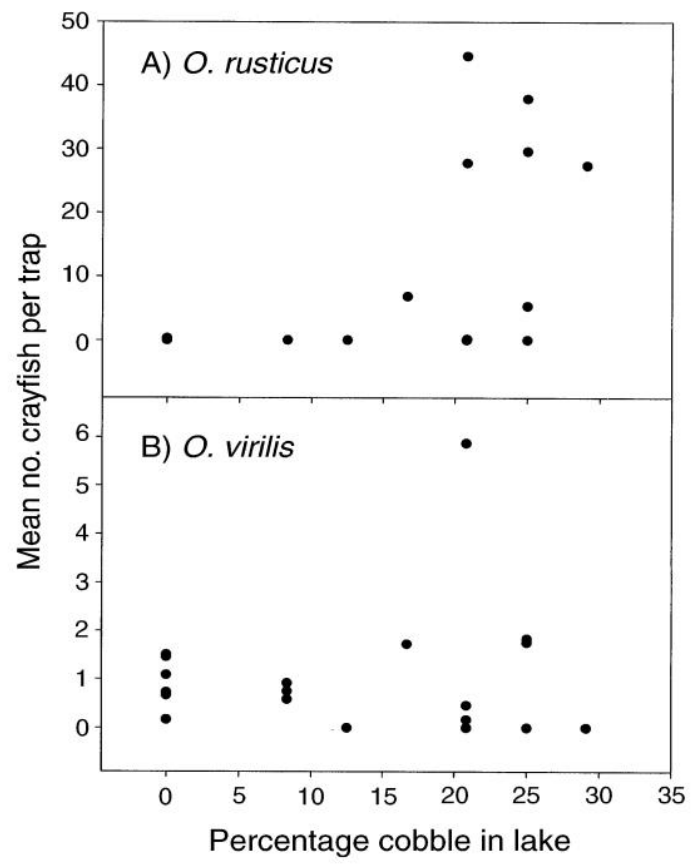

Fig. 3. Mean lake-wide abundance of $O$. rusticus and $O$. virilis as a function of percentage cobble in the littoral zones of 21 northern Wisconsin lakes during the summer of 1987.

Table 2. Final species scores from a canonical correspondence analysis (CCA) with lakewide abundances (crayfish, mean individuals per trap; fish, mean biomass per transect) of O. rusticus $(\mathrm{OR}), O$. virilis $(\mathrm{OV})$, yellow perch (YP), rock bass (RB), smallmouth bass (SMB), walleye (WE), and largemouth bass (LMB) included in the main species matrix and percentage cobble, surface area (ha), and maximum depth (m) in the secondary lake matrix.

\begin{tabular}{lccccc}
\hline \hline & \multicolumn{2}{c}{ CCA axis 1} & & \multicolumn{2}{c}{ CCA axis 2 } \\
\cline { 2 - 3 } \cline { 5 - 6 } Species & Final & & & Final & \\
variable & score & $r$ & & score & $r$ \\
\hline OR & -1.871 & $-0.74^{*}$ & & 5.497 & -0.38 \\
OV & 0.433 & -0.04 & & -0.696 & -0.27 \\
YP & 1.402 & $0.40^{*}$ & & 0.456 & -0.16 \\
RB & 0.312 & -0.12 & & 0.162 & -0.21 \\
SMB & -0.463 & -0.25 & & -0.525 & -0.16 \\
WE & -0.812 & $-0.63^{*}$ & & -0.278 & -0.26 \\
LMB & 0.543 & 0.00 & & -1.623 & -0.24 \\
\hline
\end{tabular}

Notes: Data were compiled for 21 northern Wisconsin lakes during the summer of 1987. Pearson correlation coefficients were generated for lake-wide abundances and species scores across lakes. For CCA axis 1 , the eigenvalue was 0.338 and the percentage variance 39.9 ; for $\mathrm{CCA}$ axis 2 , the eigenvalue was 0.027 and the percentage variance 3.2

* Significant at $P<0.05$.

Because the CCA suggested that largemouth bass, yellow perch, rock bass, and smallmouth bass may be negatively associated with $O$. rusticus (Table 2), we combined the biomass of these fishes to further explore potential effects on crayfish. Densities of $O$. rusticus 
and $O$. virilis were differentially related to fish biomass, depending on spatial scale. Among sectors within lakes, only $4 \%$ of rerandomized data sets produced more significant patterns than that between fish biomass and $O$. rusticus (2DKS; Fig. 5A). The mean and variance of $O$. rusticus was high below $141 \mathrm{~g}$ fish per transect and effectively 0 above this apparent threshold (Fig. 5A). A similar pattern occurred at $217 \mathrm{~g}$ fish for $O$. virilis at the sector-specific scale (2DKS, $P=0.06$, Fig. 5B). Similar to the sector-specific pattern, the mean and variance in lakewide abundance of $O$. rusticus declined to 0 above $128 \mathrm{~g}$ fish (2DKS, $P=0.06$; Fig. 5C). In contrast, $O$. virilis densities varied between 0 and 2 below $151 \mathrm{~g}$ fish and, above this biomass, never equaled 0 and exceeded 5 in one lake (2DKS, $P=0.02$; Fig. 5D).

\section{Discussion}

Habitat as well as fish composition and abundance were differentially associated with the size structure and abundance of the invader $O$. rusticus and the native $O$. virilis. Orconectes propinquus, the previous invader, was only abundant in Trout Lake, making it difficult to generate general conclusions about its distribution. The direction of species and habitat associations depended on spatial scale, with important implications for community assembly and invasion processes.

\section{Habitat}

Crayfish occurrence was linked to habitat in Trout Lake. Orconectes rusticus did not occur at all sites because it had not completely dispersed by 1990 (Byron and Wilson 2001). Although $O$. virilis actively seeks cobble to evade predators (Hill and Lodge 1994), it occurred exclusively in macrophytes. Interactions between $O$. virilis and the invaders probably resulted in its exclusion from cobble (Capelli and Munjal 1982, Hill et al. 1993, Garvey et al. 1994, Hill and Lodge 1999). Hence, local species composition and perhaps diversity are strongly affected by competitive interactions for habitat patches that provide "enemy free space" (Jeffries and Lawton 1984, Hill and Lodge 1994).

Because abundance of $O$. rusticus but not $O$. virilis increased across lakes with increased cobble (also see Lodge and Hill 1994), greater depths, and larger surface areas, these factors appear to influence the successful establishment and likely dispersal of $O$. rusticus (Kershner and Lodge 1995, Byron and Wilson 2001). However, in lakes with high cobble, O. rusticus abundance varied substantially, probably as a function of factors such as predator abundance (see Discussion: Predation and crayfish size structure) and history of introduction. If introduction history is important, understanding how O. rusticus is transported among lakes will be critical (Buchan and Padilla 1999).

\section{Predation and crayfish size structure}

Body size often mediates interactions among prey and their predators (Zaret 1980, Stein et al. 1988, Mather and Stein 1993). Size-specific predation risk varies with habitat for crayfish (Garvey et al. 1994, Kershner and Lodge 1995). Similar to Stein (1977), average crayfish size in Trout Lake was small in cobble and large in macrophyte, regardless of species. Although small crayfish use interstices to evade consumption in cobble, large spaces may be limited for large individuals. Indeed, fishes selected large crayfish over more abundant small ones in cobble. In macrophytes, small crayfish were selected by fish although large crayfish were more prevalent. Given no structure, fish tend to select the smallest crayfish to minimize handling costs (Stein 


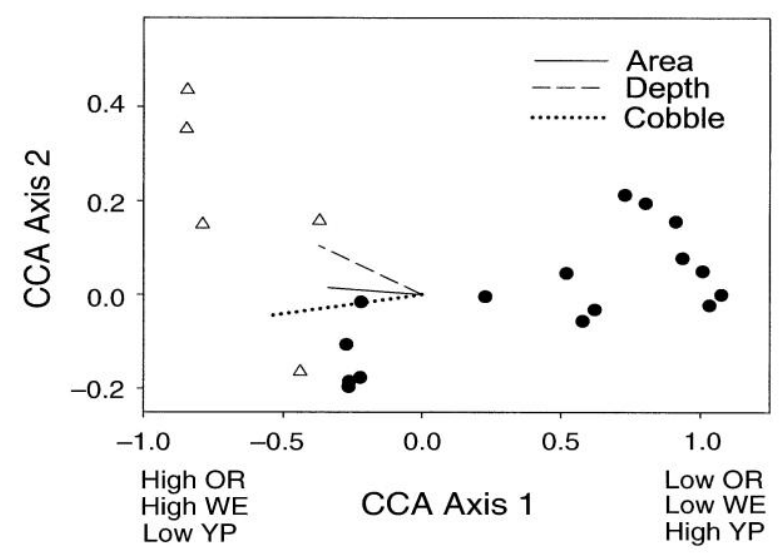

Fig. 4. Results of canonical correspondence analysis (CCA) including lake-wide mean abundances of $O$. rusticus (OR), O. virilis (OV), yellow perch (YP), rock bass (RB), smallmouth bass (SMB), walleye (WE), and largemouth bass (LMB) in the species matrix and surface area (ha), maximum depth (m), and percentage cobble in the environmental matrix. Data derive from 21 northern Wisconsin lakes sampled during the summer of 1987. Open triangles on the ordination plot are lakes with O. rusticus mean trap densities $>20$. Lines depict the direction and magnitude of biplot scores for the environmental data.

1977). It appears that macrophytes do not provide a size-based refuge. The shift to larger sizes also may have occurred if large crayfish moved from cobble into macrophytes to forage (Hill and Lodge 1994, 1999).

Size-selective fish predation also may explain species-specific patterns of crayfish occurrence. Cobble is an important nursery habitat for crayfish (Stein 1977). Hence, competition between $O$. virilis and the invaders in cobble would result in the native's greater removal as it grew through vulnerable, early life stages (DiDonato and Lodge 1993, Garvey et al. 1994), similar to habitat-mediated ontogenetic bottlenecks in other communities (Neill 1975, Persson and Greenberg 1990, Olson et al. 1995). In macrophytes, the large average size of O. virilis relative to the invaders would provide a predatory size refuge for adults. Indeed, O. virilis was consumed proportionally less than the congeners in macrophytes in Trout Lake and subsequently only occurred in this habitat. Although abundant macrophytes may facilitate the persistence of $O$. virilis, we must explore how cobble affects recruitment of $O$. virilis to determine to what extent this species can persist when cobble is restricted or absent.

\section{Fish assemblages and crayfish}

Largemouth bass, yellow perch, and rock bass frequently consumed crayfish in Trout Lake, which was supported by the strong decline in $O$. rusticus beyond an intermediate biomass of fishes both within and across lakes. Within lakes, $O$. virilis abundance also declined beyond a threshold fish abundance. At the whole-lake scale, the opposite pattern emerged-abundance of this species was positive beyond a threshold predator biomass. Although either the abundance or trapability (see Collins et al. 1983) of $O$. virilis should be reduced by fishes at individual sites, the positive across-lake relationship may have arisen due to the negative effect of $O$. rusticus in low fish lakes and perhaps abiotic factors (e.g., "bottom-up'" effects of lake productivity) that facilitated both fish growth and $O$. virilis density in high fish lakes. Lake-wide densities of $O$. virilis were low even when invaders were absent and predators rare, suggesting this species is typically scarce. 


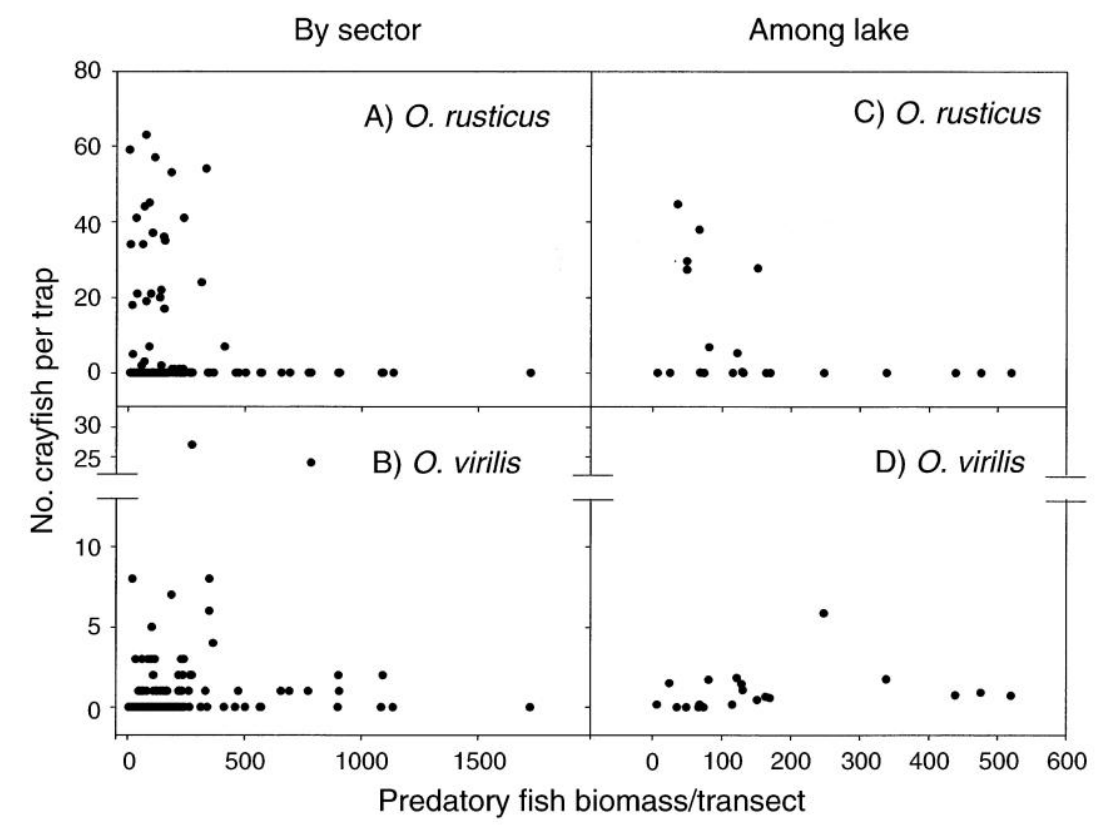

Fig. 5. (A, B) Sector and (C, D) mean lake-wide abundance of $O$. rusticus and $O$. virilis as a function of the combined biomass of yellow perch, largemouth bass, and rock bass in the littoral zones of 21 northern Wisconsin lakes during the summer of 1987.

As with all observational studies, we need to examine both possible directions of causality for the correlations among the taxa. Crayfish, in particular $O$. rusticus, may reduce fish success by consuming fish eggs and larvae (Dorn and Mittelbach 1999). Therefore, fishes that spawn on benthic substrate would be negatively affected, although nest-guarding behavior should mitigate crayfish predation. Among lakes, high $O$. rusticus corresponded with low but not zero fish biomass. Yet, the lowest fish abundances occurred in lakes with low crayfish, suggesting that others factors limit fish. Walleye, a species that spawns on gravel with no parental care, should be very susceptible to $O$. rusticus predation. However, the positive association between this species and $O$. rusticus in lakes makes a negative effect of crayfish suspect. Still, young walleye are stocked into many of these lakes to supplement natural reproduction, potentially masking crayfish effects. Without experimental verification, the importance of this potential interplay between fish and crayfish is unknown.

Habitat may directly affect the abundance and distribution of fishes, thereby indirectly affecting crayfish. However, both within Trout Lake and among lakes, the sizes and abundance of fishes varied among sites, yielding no detectable habitat differences. Thus, the robust habitatspecific differences in crayfish abundance and species composition probably cannot be attributed to habitat-mediated fish assemblages. It is important to note that fish are mobile and may forage among habitats, potentially masking site-specific linkages between fish and crayfish.

\section{Scale dependence of interactions}

The establishment of $O$. rusticus and its ability to replace $O$. virilis may depend on the spatial scale of inquiry (Lodge et al. 1998, Levine 2000). Across sectors in lakes, O. rusticus and $O$. virilis were negatively associated, confirming that the more aggressive and less susceptible $O$. rusticus should strongly negatively affect $O$. virilis and perhaps $O$. propinquus at local contact 
zones (Garvey et al. 1994). Although direct interactions between the congeners are likely, increases in total crayfish density at contact areas may temporarily increase fish density, perhaps facilitating the predatory removal of the less abundant $O$. virilis (i.e., apparent competition, Holt 1977). Although biotic interactions may rapidly shift species composition at contact zones, fish predation may hinder the dispersal of $O$. rusticus at the whole-lake scale. Interestingly, $O$. rusticus and $O$. virilis were not negatively associated at this scale. Low power may be responsible, because only a subset of the 21 lakes contained $O$. rusticus. Conversely, O. rusticus may only rapidly disperse and replace $O$. virilis at the whole-lake scale when predators are scarce and cobble is abundant. Understanding the scale dependency of biotic interactions is critical for predicting rates of replacement and invasion, as it is in general models of community assembly (Persson et al. 1999, Weiher and Keddy 1999).

\section{Generality}

Many species that co-exist with predators use cryptic morphological characteristics and reduced activity to evade detection (Peacor and Werner 2001). Orconectes virilis reduces activity more with fish than the invading congeners (Garvey et al. 1994), suggesting that it possesses these adaptations. Aggressive invaders such as $O$. rusticus may dramatically shift species composition if less aggressive, more cryptic natives such as $O$. virilis are present. However, these highly active or aggressive characteristics may increase their vulnerability, excluding them from systems with abundant predators. These differences among closely related species reflect apparent tradeoffs of residing in different environments (Skelly 1995, Van Buskirk et al. 1997). Identifying the invasion potential of a species may involve weighing the positive influence of these traits on its ability to replace natives at local contact zones against their negative influence on system-wide predatory mortality.

Both physical attributes of the system and native species should affect the ability for an invader to establish (Kolar and Lodge 2001). Cobble, and to a lesser extent lake depth and surface area, appear to be good predictors of the potential for $O$. rusticus to establish and spread (Lodge and Hill 1994, Kershner and Lodge 1995). Managers might prioritize lakes with these characteristics to receive elevated protection from illegal introductions or enhanced eradication programs if the invader is newly established (Myers et al. 2000). Orconectes rusticus can dramatically reduce macrophytes within lakes through mechanical clipping (Lodge et al. 1994, Wilson 2002). Given the apparent dependence of $O$. virilis on macrophytes in Trout Lake, habitat alteration by the invader may further contribute to this native's decline, necessitating conservation of macrophyte to protect $O$. virilis (see Wilson 2002). Because only a subset of fishes appeared to strongly affect $O$. rusticus success, we must understand the linkages between invaders and their predators. Differential recruitment and harvest of ecologically and economically important fishes may influence $O$. rusticus, providing a direct linkage between the policies of resource managers and the spread of an invader (see Stewart et al. 1981 for example in the Great Lakes).

With global homogenization of biota well underway, quantitative methods for predicting the invasibility of species are sorely needed. Clearly, policies for curbing the further spread of $O$. rusticus require a quantitative grasp of the interrelationships between fishes and cobble availability. Our results are compelling but correlative. Other factors must be explored, including terrestrial predators, lake productivity, and crayfish effects on fish. Because mechanisms affecting invasions appear to be scale dependent, determining how invading species establish, interact, and disperse must be approached at spatial scales relevant to each underlying process. 


\section{Acknowledgments}

A portion of this research was supported through an REU supplement to NSF grants BSR 85-00775 and BSR 89-07691 in collaboration with Ken Brown and Alan Covich. We thank Tom Frost and the University of Wisconsin-Madison, Trout Lake Station for providing equipment and space. Anna Hill and Mark Kershner provided useful input during the study. Comments by Mark Kershner, Sharon Lawler, Per Nyström, and an anonymous reviewer greatly improved the manuscript. Finally, we thank Guy DiDonato for his extensive help in the field.

\section{Literature Cited}

Abrams, P. A. 1996. Evolution and the consequences of species introductions and deletions. Ecology 77:1321-1328.

Buchan, L. A. J., and D. K. Padilla. 1999. Estimating the probability of long-distance overland dispersal of invading aquatic species. Ecological Applications 9:254-265.

Butler, M. J., and R. A. Stein. 1985. An analysis of the mechanisms governing species replacements in crayfish. Oecologia 66:168-177.

Byron, C. J., and K. A. Wilson. 2001. Rusty crayfish (Orconectes rusticus) movement within and between habitats in Trout Lake, Vilas County, Wisconsin. Journal of the North American Benthological Society 20:606-614.

Capelli, G. M. 1982. Displacement of northern Wisconsin crayfish by O. rusticus (Girard). Limnology and Oceanography 27:741-745.

Capelli, G. M., and B. M. Munjal. 1982. Aggressive interactions and resource competition in relation to species displacement among crayfish of the genus Orconectes. Journal of Crustacean Biology 2:486-492.

Carlander, K. D. 1969. Handbook of freshwater fishery biology. Volume I. Iowa State University Press, Ames, Iowa, USA.

Carlander, K. D. 1977. Handbook of freshwater fishery biology. Volume II. Iowa State University Press, Ames, Iowa, USA.

Carlander, K. D. 1997. Handbook of freshwater fishery biology. Volume III. Iowa State University Press, Ames, Iowa, USA.

Chesson, J. 1978. Measuring preference in selective predation. Ecology 59:211-215.

Chesson, J. 1983. The estimation and analysis of preference and its relationship to foraging models. Ecology 64:1297-1304.

Collins, N. C., H. H. Harvey, A. J. Tierney, and D. W. Dunham. 1983. Influence of predatory fish density on trapability of crayfish in Ontario lakes. Canadian Journal of Fisheries and Aquatic Sciences 40:1820-1828.

Corey, S. 1988. Comparative life histories of two populations of the introduced crayfish Orconectes rusticus (Girard, 1852) in Ontario. Crustaceana 55:29-38.

DiDonato, G. T., and D. M. Lodge. 1993. Species replacements among Orconectes crayfishes in Wisconsin lakes: the role of predation by fish. Canadian Journal of Fisheries and Aquatic Sciences 50:1484-1488.

Dorn, N. J., and G. G. Mittelbach. 1999. More than predator and prey: a review of interactions between fish and crayfish. Vie et Milieu 49:229-237.

Elton, C. S. 1958. The ecology of invasions by plants and animals. Methuen and Company, London, UK.

Garvey, J. E., E. A. Marschall, and R. A. Wright. 1998. From star charts to stoneflies: detecting relationships in continuous bivariate data. Ecology 79:442-447.

Garvey, J. E., and R. A. Stein. 1993. Evaluating how chela size influences the invasion potential of an introduced crayfish. American Midland Naturalist 129:172-181.

Garvey, J. E., R. A. Stein, and H. M. Thomas. 1994. Assessing how fish predation and interspecific prey competition influence a crayfish assemblage. Ecology 75:532-547.

Hill, A. M., and D. M. Lodge. 1994. Diel changes in resource demand: competition and predation in species replacement among crayfishes. Ecology 75:2118-2126.

Hill, A. M., and D. M. Lodge. 1999. Replacement of resident crayfishes by an exotic crayfish: the roles of competition and predation. Ecological Applications 9:678-690.

Hill, A. M., D. M. Sinars, and D. M. Lodge. 1993. Invasion of an occupied niche by the crayfish Orconectes rusticus: potential importance of growth and mortality. Oecologia 94:303-306.

Holt, R. D. 1977. Predation, apparent competition, and the structure of prey communities. Theoretical Population Biology 12:197-229.

Holway, D. A., and A. V. Suarez. 1999. Animal behavior: an essential component of invasion biology. Trends in Ecology and Evolution 14:328-330.

Jeffries, M. J., and J. H. Lawton. 1984. Enemy free space and the structure of aquatic communities. Biological 
Journal of the Linnean Society 23:269-286.

Kershner, M. W., and D. M. Lodge. 1995. Effects of littoral habitat and fish predation on the distribution of an exotic crayfish, Orconectes rusticus. Journal of the North American Benthological Society 14:414-422.

Kiesecker, J. M., and A. R. Blaustein. 1998. Effects of introduced bullfrogs and smallmouth bass on the microhabitat use, growth, and survival of native red-legged frogs (Rana aurora). Conservation Biology 12:776-787.

Kolar, C. S., and D. M. Lodge. 2001. Progress in invasion biology: predicting invaders. Trends in Ecology and Evolution 16:199-204.

Levine, J. M. 2000. Species diversity and biological invasions: relating local process to community pattern. Science 288:852-4.

Lodge, D. M. 1993. Biological invasions: lessons for ecology. Trends in Ecology and Evolution 8:133-136.

Lodge, D. M., and A. M. Hill. 1994. Factors governing species composition, population size, and productivity of cool-water crayfishes. Nordic Journal of Freshwater Research 69:111-136.

Lodge, D. M., M. W. Kershner, J. E. Aloi, and A. P. Covich. 1994. Effects of an omnivorous crayfish (Orconectes rusticus) on a freshwater littoral food web. Ecology 75:1265-1281.

Lodge, D. M., T. K. Kratz, and G. M. Capelli. 1986. Long-term dynamics of three crayfish species in Trout Lake, Wisconsin. Canadian Journal of Fisheries and Aquatic Sciences 43:993-998.

Lodge, D. M., R. A. Stein, K. M. Brown, A. P. Covich, C. Bronmark, J. E. Garvey, and S. P. Klosiewski. 1998. Predicting impact of freshwater exotic species on native biodiversity: challenges in spatial scaling. Australian Journal of Ecology 23:53-67.

Lodge, D. M., C. A. Taylor, D. M. Holdich, and J. Skurdal. 2000. Nonindigenous crayfishes threaten North American freshwater biodiversity: lessons from Europe. Fisheries 25: 7-20.

Manly, B. F. J. 1991. Randomization and Monte Carlo methods in biology. Chapman and Hall, New York, New York, USA.

Mather, M. E., and R. A. Stein. 1993. Direct and indirect effects of fish predation on the replacement of a native crayfish by an invading congener. Canadian Journal of Fisheries and Aquatic Sciences 50:1279-1288.

McCune, B., and M. J. Mefford. 1999. PC-ORD: multivariate analysis of ecological data. Version 4. MjM Software Design, Gleneden Beach, Oregon, USA.

Miller, T. E., J. M. Kneitel, and J. H. Burns. 2002. Effect of community structure on invasion success and rate. Ecology 83:898-905.

Myers, J. H., D. Simberloff, A. M. Kuris, and J. R. Carey. 2000. Eradication revisited: dealing with exotic species. Trends in Ecology and Evolution 15:316-320.

Neill, N. E. 1975. Experimental studies of microcrustacean competition, community composition, and efficiency of resource utilization. Ecology 56:809-826.

Neter, J., W. Wasserman, and M. H. Kutner. 1990. Applied linear statistical models: regression, analysis of variance, and experimental designs. Irwin Publishing, Boston, Massachusetts, USA.

Northcote, T. G. 1988. Fish in the structure and function of freshwater ecosystems: a "top-down" view. Canadian Journal of Fisheries and Aquatic Sciences 45:361-379.

Olsen, T. M., D. M. Lodge, G. M. Capelli, and R. J. Houlihan. 1991. Mechanisms of impact of an introduced crayfish (Orconectes rusticus) on littoral congeners, snails and macrophytes. Canadian Journal of Fisheries and Aquatic Sciences 48:1853-1861.

Olson, M. H., G. G. Mittelbach, and C. W. Osenberg. 1995. Competition between predator and prey: resource-based mechanisms and implications for stage-structured dynamics. Ecology 76:1758-1771.

Peacor, S. D., and E. E. Werner. 2001. The contribution of trait-mediated indirect effects to the net effects of a predator. Proceedings of the National Academy of Sciences (USA) 98:3904-3908.

Persson, L., P. Bystrom, E. Wahlstrom, J. Andersson, and J. Hjelm. 1999. Interactions among size-structured populations in a whole-lake experiment: size- and scale-dependent processes. Oikos 87:139-156.

Persson, L., and L. A. Greenberg. 1990. Optimal foraging and habitat shift in perch (Perca fluviatilis) in a resource gradient. Ecology 71:1699-1713.

SAS. 1996. SAS/STAT user guide. Version 6, Volumes 1 and 2. SAS Institute, Cary, North Carolina, USA.

Seaburg, K. G. 1957. A stomach sampler for live fish. Progressive Fish Culturist 19:137-139.

Sih, A., P. Crowley, M. McPeek, J. Petranka, and K. Strohmeier. 1985. Predation, competition, and prey communities: a review of field experiments. Annual Review of Ecology and Systematics 16:269-311.

Skelly, D. K. 1995. A behavioral trade-off and its consequences for the distribution of Pseudacris treefrog larvae. Ecology 76:150-164.

Söderbäck, B. 1990. Interspecific dominance relationship and aggressive interactions in the freshwater crayfishes 
Astacus astacus (L.) and Pacifasticus leniusculus (Dana). Canadian Journal of Zoology 69:1321-1325.

Stein, R. A. 1977. Selective predation, optimal foraging, and the predator-prey interaction between fish and crayfish. Ecology 58:1237-1253.

Stein, R. A., D. R. DeVries, and J. M. Dettmers. 1995. Food web regulation by a planktivore: exploring the generality of the trophic cascade hypothesis. Canadian Journal of Fisheries and Aquatic Sciences 52:25182526.

Stein, R. A., S. T. Threlkeld, C. D. Sandgren, W. G. Sprules, L. Persson, E. E. Werner, W. E. Neill, and S. I. Dodson. 1988. Size-structured interactions in lake communities. Pages 161-180 in S. R. Carpenter, editor. Complex interactions in lake communities. Springer-Verlag, New York, New York, USA.

Stewart, D. J., J. F. Kitchell, and L. B. Crowder. 1981. Forage fishes and their salmonid predators in Lake Michigan. Transactions of the American Fisheries Society 110:751-763.

Van Buskirk, J., S. A. McCollum, and E. E. Werner. 1997. Natural selection for environmentally induced phenotypes in tadpoles. Evolution 51:1983-1992.

VanderZanden, M. J., J. M. Casselman, and J. B. Rasmussen. 1999. Stable isotope evidence for the food web consequences of species invasions in lakes. Nature 401:464-467.

Vitousek, P. M. 1990. Biological invasions and ecosystem processes: towards an integration of population biology and ecosystem studies. Oikos 57:7-13.

Weiher, E., and P. Keddy. 1999. Ecological assembly rules: perspectives, advances, retreats. Cambridge University Press, Cambridge, UK.

Wellborn, G. A., D. K. Skelly, and E. E. Werner. 1996. Mechanisms creating community structure across a freshwater habitat gradient. Annual Review of Ecology and Systematics 27:337-363.

Wilson, K. A. 2002. Impacts of the invasive rusty crayfish (Orconectes rusticus) in northern Wisconsin lakes. Dissertation. University of Wisconsin, Madison, Wisconsin, USA.

Zaret, T. M. 1980. Predation and freshwater communities. Edward Brothers, Ann Arbor, Michigan, USA. 